\title{
Development of planning and scheduling reference models using the aris method \& toolset
}

\author{
D. Little, J. K. Porter ${ }^{1)}$, M. Peck, R. Rollins \\ Manufacturing Systems Research Group \\ School of Engineering, The University of Huddersfield \\ Huddersfield, HD1 3DH, UK \\ Tel: +441484 473339 \\ Fax: +44 1484472340 \\ 1) Liverpool John Moores University \\ e-mail:d.little@hud.ac.uk
}

\begin{abstract}
Most manufacturing firms are under considerable pressure to increase their flexibility and responsiveness within the market. Key business processes concerned with responsiveness include information systems for demand management and manufacturing control. Overall, information systems account for almost a quarter of all IT investment within major manufacturing companies and much of this is currently being spent with ERP vendors who include BAAN, Oracle, SAP and MK Manufacturing (Vortman, 1998).

It is estimated that Seventy-five percent of these firms still use information systems based on the MRP/MRPII paradigm regardless of its suitability to their specific requirements and its inherent inability to be responsive to short term changes in customer needs. Whilst simpler systems (JT for example) appear to work well for high volumes of standard products, the market trend in many industries is towards a reduction of product volume and increase variety to the extent that computer support for manufacture becomes essential.

Recent research (Little et al, 1995) has shown that one key area for all manufacturing companies is the performance of the manufacturing control function. There is a wide range of generic proprietary software available that meets a company's planning and scheduling requirements with varying degrees of success. The difficulty experienced by many companies is not only in examining available software, but also in understanding the match between their business needs and the capabilities of that software. A poor match typically limits the ability of a firm to respond to market changes and is likely to inhibit company
\end{abstract}


growth. This is a particular problem for an expanding small and medium enterprise (SME).

The ongoing research project funded by the UK Engineering and Physical Sciences Research Council (EPSRC) covered by this paper (Little D and Porter J $\mathrm{K}, 1996-99)$ is aimed at developing novel planning and scheduling reference models for industrial sectors where the MRPII paradigm is not a good fit. It gives an overview of the research method developed, explains the data capture method used for the case study companies and the use of Scheer's (Scheer, 1994) enterprise modeling tool, ARIS, for the production of the extended event process chains which underpin the sector reference models.

\section{Keywords}

Manufacturing information systems, planning and scheduling, reference models, enterprise modelling,

\section{OBJECTIVES}

The main aim of the Planning and Scheduling Reference Model project is to provide companies with a means to identify more appropriate planning and scheduling architectures to enable increased agility in responding to changing customer requirements. This will be done by the production of a simple self-audit method based upon the reference models to be used by company management.

The self-audit method will facilitate an examination of current planning and scheduling processes within the target company and allow these to be benchmarked against generic current practice employed in a range of firms operating in the same sector. In this way, beneficial variances or omissions in company systems can be identified and incorporated in a modified reference model. The resulting architecture can then be used to communicate the requirements internally or to a software vendor or developer.

\section{RESEARCH APPROACH}

An earlier project examining best UK practice in short term scheduling [2] identified a number of industrial sectors where, although the MRP/MRPII paradigm was in common use, it was not a good fit. These included the following sectors:

- Garment production

- Engineer to order capital equipment

- Batch manufacture of set process order production

- Fast moving consumer goods (FMCG)

The research was designed to undertake four detailed case studies in each of first three sectors above using a process mapping approach. A detailed map of the order fulfilment process was produced for each company in each sector and subject to precise analysis to identify key sub-components of the main process and any 
associated critical success factors. The output from the analysis was a generic sector reference model produced as a prototype, along with critical success factors for the process and a definition of critical business sub-process components, which included a detailed data dictionary. The main stages in the research method are set out below:

- Identify the process to be modelled stating the viewpoints being taken.

- Use a 'top down' approach to develop an overview of company structure, strategy and operation using:

- a Function Relationship Diagram to represent the functional linkages occurring during the process.

- a GRAI Grid to represent the decision making structure within the company.

- an organisational hierarchy chart.

- Use a 'bottom up' approach to identify the sub-processes and their characteristics by generating a Data Flow Diagram to depict the flow of resources and paperwork from activity to activity within the process or sub-processes using IDEFo, including informal communications and decisions.

- Generate a Data Capture Grid to detail all the activities of the sub-processes. This can be used to analyse value-adding time in the process by use of a timecompression tool produced by the research team.

- Validate the models produced with the case study companies.

- Input the data from each case study company into ARIS to produce an eEPC model for the company and validate this with company management.

- Analyse the process maps for the case study companies within a particular industrial sector to produce a high level 'process overview' and identify key business process sub-components and associated 'critical success factors' for the sub-processes.

- From the above, develop a draft generic planning and scheduling reference model (PSRM) for that industrial sector with detailed specification of key business subprocess components, supported by a data dictionary description and critical success factors.

- Produce a simple self-audit method for company management based upon the sector reference models which examines the firm's current approach to planning and scheduling and identifies discrepancies with the sector reference model.

\section{DATA CAPTURE FOR CASE STUDY COMPANIES}

A by-product of the research is the development of a simple process mapping approach for planning and scheduling within case study companies which can focus upon how value is added within the manufacturing supply chain. To support the investigation, a novel structured method was developed specifically for data capture within the case study companies to provide validated models of processes and activities. 
The method is based upon a series of visits to the case study company which typically take about two days. During the visits, four techniques are used to capture the inputs to the ARIS modelling:

- Function Relationship Diagrams

- Grai Grids

- Data Flow Diagrams

- Time Capture Grids.

Once validated, the data from these first phase models is used to construct a series of process models within the integrated views of ARIS (Architecture for Integrated Information Systems) developed by Professor Scheer of IDS GmbH. ARIS provides a structured framework and powerful software tool to aid the modelling process.

There are two distinct advantages in using a method and toolset such as ARIS to model the key processes of a business:

The graphical representation of models

Using the ARIS-Tool set provides a simple and consistent graphical representation of a business process. A shared common language is available, improving communication and understanding between all parties engaged in the modeling process.

- The functionality of the toolset

- The ability to provide comprehensive and integrated models of business processes. Integrated in this context means that individual models constructed within the tool are not isolated but are linked by the common objects that they contain.

The main ARIS output used by the research team takes the form of an extended event process chain. This is typically a large document that is output from a plotter. Although eEPCs are extensive, the team's experience indicates that they can readily be validated by company management.

\section{DEVELOPMENT OF REFERENCE MODELS}

The eEPCs and the Grai Grids for all case study companies within a particular sector are then examined for similarities and differences and the results summarised in the form of a higher level 'process overview'. From this process overview, the main components of the business process for the sector are identified and key business process sub-components (BPSCs) highlighted. It is these BPSCs that are critical to the performance of a company operating within the particular sector.

The critical factors for each key BPSC identified are then identified along with the supporting logic for the key BPSC with inputs and outputs recorded in a data dictionary. This level of detail will enable company management to define system requirements for significant variances or omissions identified when using the selfaudit method. In this way, the generic model of current practice within a range of firms can be used to identify opportunities for changes within the systems 
architecture of another company operating within the same sector and then indicate the characteristics of appropriate process sub-components.

\section{CONCLUSIONS}

Using a business process mapping approach within a number of case study companies operating within similar business environments, the project identifies the different methods of planning and scheduling used in these companies and the key business process components that support this. Once identified, these architectures can be used to develop reference models to facilitate self-evaluation of supporting systems with a view to encourage positive change within a manufacturing organisation.

An aspect of the investigation is the success of the case study companies at meeting their overall business goals and the effect that their planning and scheduling methods has had on the degree of this success. These reference models will then be referenced against the existing company planning \& scheduling procedures and a gap-analysis made to highlight areas where opportunities for improvement exist. This profile can then be used to communicate the requirements of the company to a software vendor by use of eEPC logic for key planning and scheduling process sub-components and the production of a data dictionary description of these.

Such detailed description will lead to clear specification of requirements for any software package purchase or the development of bespoke software. In this way the needs of the purchaser will be closely matched.

One key feature that is becoming apparent from the two prototype sector reference models produced is the increasing integration between even the smallest firm and its suppliers and customers. Such an increase in integration can create the extended enterprise, as outlined by Yusuf (Yusuf, 1996). The critical difference between the typical architecture arising from this project and that of most ERP solutions is that it is very focused upon the specific requirement of a particular business sector. This provides a lean and responsive system that can be easily adapted to changing business requirements.

\section{REFERENCES}

Vortman H, (1988). Evolution of ERP systems. Proceedings of the IFIP WG5.7 Conference, Troon, 26-28 August, Kluwer, ISBN 0-412-82710-7.

Little D, Kenworthy J G, Porter J K and Jarvis P C, (1995). Investigation of best practice in UK short term scheduling. EPSRC GR/H20473, Final Report. The University of Liverpool,

Little D and Porter J K, (1996-99). EPSRC (CDP) GR/L22003 £251,630: Planning and Scheduling Reference Models for different industrial sectors. 
Collaborators: British Steel, Cincom (UK), Cussins, Couristan Carpets and IOM. (WithMr M Peck \& Mr R Rollins).

Scheer A-W, (1994). Business Process Engineering, Reference Models for Industrial Enterprises, Springer-Verlag, Berlin-Heidelberg, ISBN 3-54058234-7.

Yususf Y Y and Little D, 1998. An empirical investigation of enterprise-wide integration of MRPII, International Journal of Operations and Production Management, Vol 18 No 1, MCB, 66-86

\section{BIOGRAPHIES}

David Little worked in industry after graduating from Loughborough University with GEC, A. Reyrolle and Molins Ltd ending up as a senior manager in their Spares Division. He then moved into higher education at Huddersfield Polytechnic Business School. Leaving to undertake research at Liverpool University where he became a senior lecturer and Sub-Dean and recently returned to the University of Huddersfield as Professor of Manufacturing Systems. Currently Director of Research and Postgraduate Studies in the School of Engineering, he is a pastpresident of the Institute of Operations Management.

Keith J Porter graduated from Manchester University in Chemistry and then completed his doctorate before moving into industry. Over a 20 year period he worked for various FMCG companies which have included Lever Brothers, Barker and Dobson and Express Foods in posts ranging from Packaging Buyer to Logistics Manager. He is currently a Senior Lecturer at Liverpool John Moores University.

Ralph Rollins started his career as an engineer and, after a number of years, gained an honours degree in Industrial Technology from Bradford Univesity. He then returned to manufacturing as a production manager with a number of companies. He joined the University as a research fellow in 1996.

Matthew Peck graduated from the University of Huddersfield with an Engineering degree and an MSc in CIM. He joined a machine tool manufacturing company to support a BAAN installation and, after a number of years, returned to the University as a research fellow in 1996. 